\title{
Unravelling the Mechanism of Ionic Fullerene Passivation for Efficient and Stable Methylammonium-free Perovskite Solar Cells
}

Sibo Li,,$+\perp$ Ke Fan,,,$+ \perp$ Yuying Cui,,$\perp$ Shifeng Leng, ${ }^{\dagger}$ Yiran Ying,,+ Wenjun Zou, ${ }^{\dagger}$ Zhiliang Liu, ${ }^{\dagger}$ Chang-Zhi Li,,$^{\S}$ Kai Yao ${ }^{* \dagger}$ and Haitao Huang

Institute of Photovoltaics/Department of Materials Science and Engineering, Nanchang University, Nanchang 330031, China

Department of Applied Physics, The Hong Kong Polytechnic University, Hung Hom, Kowloon, Hong Kong, China

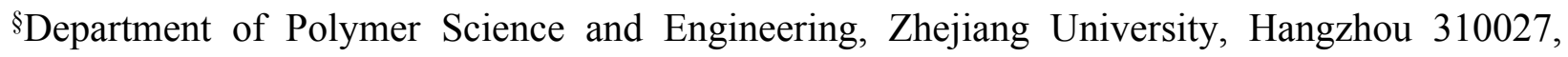
China 
Starting Materials. $\mathrm{PbI}_{2}$ (99.999\%), $\mathrm{PbBr}_{2}$ (99.999\%), CsI (99.999\%), ethyl acetate (anhydrous, 99.9\%), DMF (anhydrous, 99.9\%) and DMSO (anhydrous, 99.9\%) were purchased from Sigma Aldrich, while $\mathrm{MABr}$ (99.99\%) and FAI (99.99\%) was purchased from TCI. N,Ndimethylpyrrolidine iodine (mPyI) was synthesized by neutralizing equimolar quantity of a $57 \%$ w/w aqueous hydriodic acid (HI) with $1.0 \mathrm{~mol} / \mathrm{L}$ ethanol solution of $\mathrm{N}$-methylpyrrole under ice bath condition. The mixture was stirred for two hours at $0{ }^{\circ} \mathrm{C}$ and then allowed to slowly reach room temperature. The white precipitate was collected after rotary evaporation of the solvent and washed thoroughly with diethyl ether. The syntheses of bFP and bFPI were carried out in the similar procedures as reported (Scheme S1). ${ }^{1}$

Device Fabrication. The ITO-coated substrates were sequentially cleaned with soap solution, water, acetone and isopropanol. The hole transporting layer was fabricated by spin-coating precursor solutions of poly(bis(4-phenyl)(2,4,6-trimethylphenyl)amine) (PTAA) solution (2 mg $\mathrm{ml}^{-1}$ in chlorobenzene) onto as-cleaned ITO substrate at a rate of 3,000 rpm for $90 \mathrm{~s}$, followed by heated in ambient air at $100{ }^{\circ} \mathrm{C}$ for 10 min. Later, a interfacial compatibilizer poly[9,9bis((N,N,Ntriethylammonium)-hexyl)-2,7-fluorene] dibromide (PFN-Br, $0.1 \mathrm{mg} \mathrm{ml}^{-1}$ ) was spincoated at $3000 \mathrm{rpm}$ for $30 \mathrm{~s}$ in order to improve the coverage of the perovskite. The CsFA perovskite $\left(\mathrm{Cs}_{0.17} \mathrm{FA}_{0.83}\right) \mathrm{Pb}\left(\mathrm{I}_{0.8} \mathrm{Br}_{0.2}\right)_{3}$ was prepared by dissolving FAI, CsI, $\mathrm{PbI}_{2}$ and $\mathrm{PbBr}_{2}$ in DMF:DMSO (3:1) to obtain a stoichiometric solution. Similarly, CsMAFA film of $\mathrm{Cs}_{0.05}\left(\mathrm{MA}_{0.17} \mathrm{FA}_{0.83}\right)_{0.95} \mathrm{~Pb}\left(\mathrm{I}_{0.8} \mathrm{Br}_{0.2}\right)_{3}$ was prepared by dissolving MABr, FAI, CsI, $\mathrm{PbI}_{2}$ and $\mathrm{PbBr}_{2}$ in DMF:DMSO (4:1) to obtain a stoichiometric solution. After stirring for $12 \mathrm{~h}, 100 \mu \mathrm{l}$ precursor solutions were spin-coated on $\mathrm{PFN}-\mathrm{Br}$ at a speed of $4000 \mathrm{rpm}$ (with a ramping rate of $2000 \mathrm{rpm}$ $\mathrm{s}^{-1}$ ) for $60 \mathrm{~s}$, after $10 \mathrm{~s} 300 \mu \mathrm{l}$ of ethyl acetate were dropped rapidly as anti-solvent. After spincast, the samples were annealed at $100^{\circ} \mathrm{C}$ for $20 \mathrm{~min}$. For the surface passivation, the passivation 
molecules (bFP, bFPI and mPyI and mPy) were dissolved in isopropanol/chlorobenzene (1:1) with the concentration of $(0.2-1.0 \mathrm{mg} / \mathrm{ml})$ and were spun at $4000 \mathrm{rpm}$ for $30 \mathrm{~s}$, in which the optimized concentration for fullerene derivates is $0.5 \mathrm{mg} / \mathrm{ml}$. Particularly, PCBM was dissolved in chlorobenzene for comparison. Finally, the samples was transferred to a thermal evaporator and the devices were finished by thermally evaporating $\mathrm{C}_{60}(30 \mathrm{~nm}), \mathrm{BCP}(8 \mathrm{~nm})$, and $\mathrm{Ag}(100$ $\mathrm{nm}$ ) in sequential order.

Characterization. Current density-voltage $(J-V)$ characteristics were measured from different scanning direction by using a Keithley 2400 source meter under AM 1.5G illumination from Enli Technology solar simulator. The output intensity was calibrated by a standard silicon solar cell. Operational stability tests was conducted under bias at the maximum power point. The effective area was defined by the shade mask $\left(0.108 \mathrm{~cm}^{2}\right)$. External quantum effciencies were obtained from an EQE system (Enli Technology Co., Ltd.). Impedance spectroscopy and capacitance-voltage measurements were measured with an Autolab potentiostat (PGSTAT30). SEM was conducted on a JSM 6701F field-emission scanning electron microscope. The absorption spectra were recorded on a UV/Vis spectrophotometer (Lambda 750). PL tests were performed by a Horiba Fluorolog system. The TRPL decay lifetimes were collected using a 520 nm pump laser, generated by a monochromator spectrograph (Omni- $\lambda 300$, Zolix) with an oscilloscope (GDS-3354, GWINSTEK). The laser pulses were the same as those used in the femtosecond TA measurements.

\section{Computational details}

The theoretical calculations were performed in the framework of density functional theory implemented in the Vienna ab initio simulation package (VASP). ${ }^{2,3}$ The generalized gradient 
approximation (GGA) with the Perdew-Burke-Ernzerhof (PBE) flavor ${ }^{4}$ was chosen as the exchange-correlation functional. The plane-wave cut-off energy of $400 \mathrm{eV}$ was employed and only gamma point was used during the geometric optimization. The convergence criteria for energy and force were set to be $10^{-5} \mathrm{eV}$ and $0.01 \mathrm{eV} \AA^{-1}$, respectively. The slab models were constructed by the $\mathrm{PbI}_{2}$-terminated (anionic) and FAI-terminated (cationic) (001) surface of the cubic $\mathrm{FAPbI}_{3}$ in $3 \times 3$ supercell. To avoid the interlayer interaction, slab model with the thickness of $50 \AA$ was applied along $\mathrm{z}$ direction, which result in $35 \AA$ and $30 \AA$ of vacuum layer between the slab and its periodic replica for the $\mathrm{PbI}_{2}$-terminated and FAI-terminated surface, respectively. Bader charge analysis ${ }^{5}$ was used to analyze the charge transfer process. 

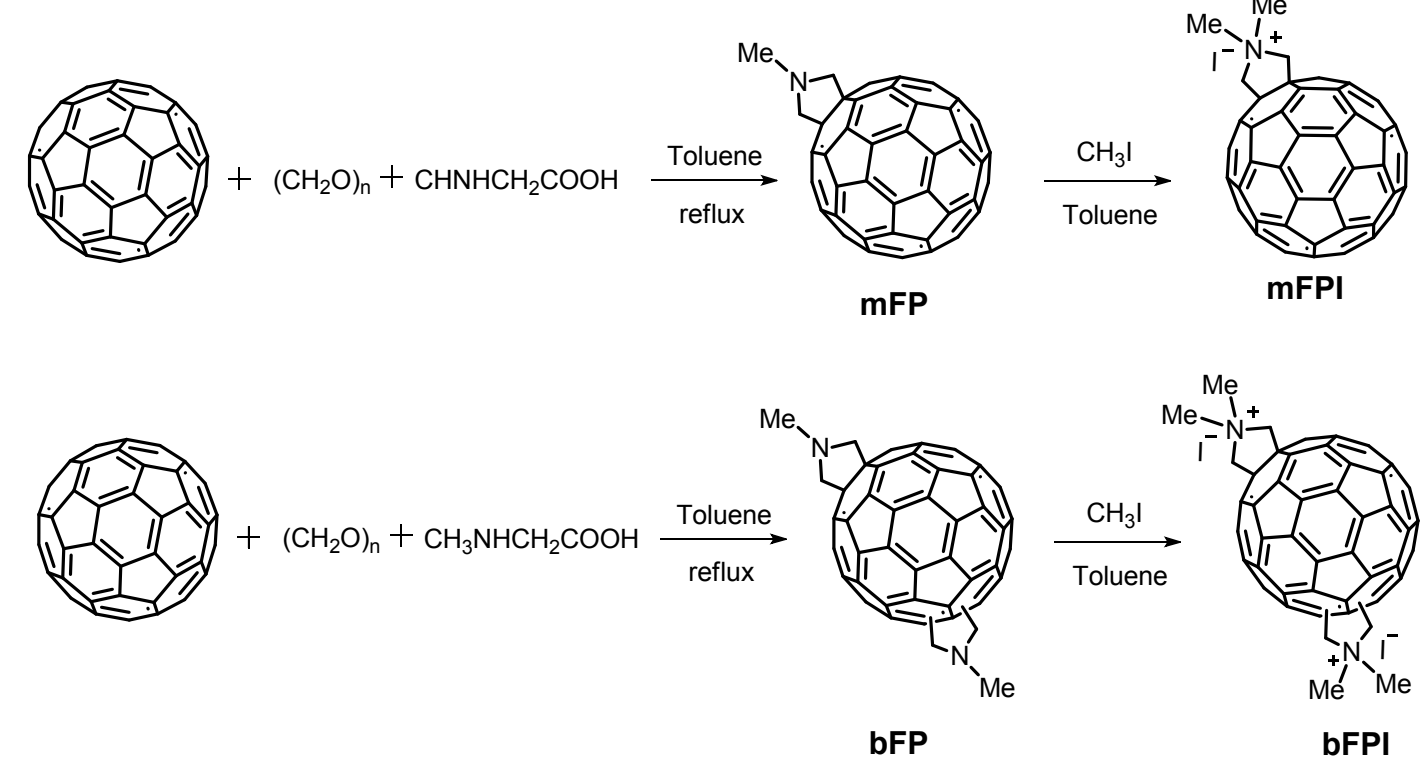

Scheme S1. Synthetic Route for mono- to bis-substituted fullerene derivates used in this work.

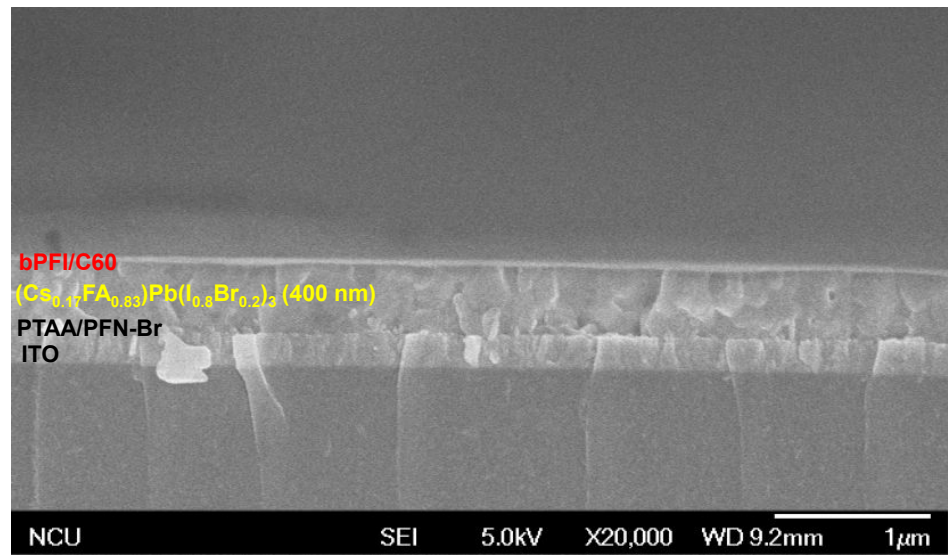

Figure S1. The cross-sectional SEM image of CsFA perovskite with electron-accepting heterostructures prepared on glass/ITO/PTAA/PFN-Br. 


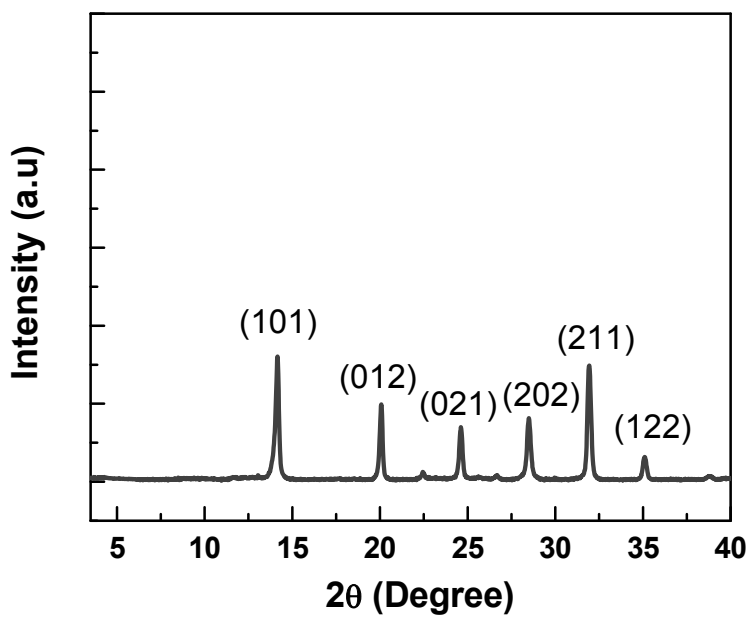

Figure S2. XRD of the as-prepared $\left(\mathrm{Cs}_{0.17} \mathrm{FA}_{0.83}\right) \mathrm{Pb}\left(\mathrm{I}_{0.8} \mathrm{Br}_{0.2}\right)_{3}$ film treated with bFPI on quartz substrate.

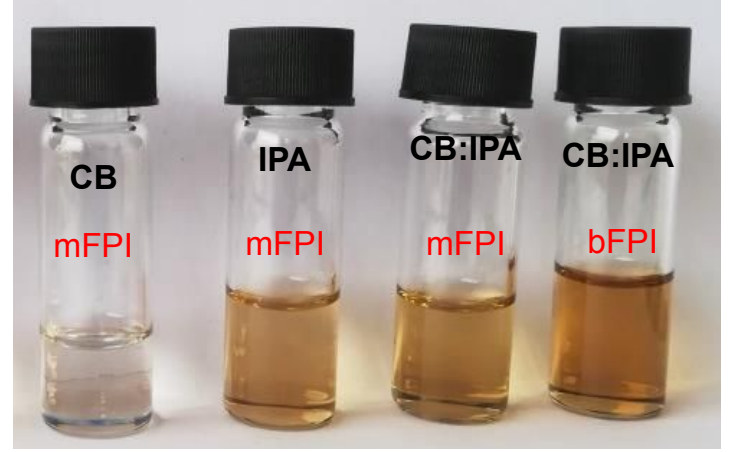

Figure S3. The image of fulleropyrrole (mFPI and bFPI) solutions. In particular, the saturation solubility of ionic fullerenes in co-solvent of CB/IPA is obvious increased from mono- to bissubstitution. Therefore, we only use bFPI and bFP for investigation. 

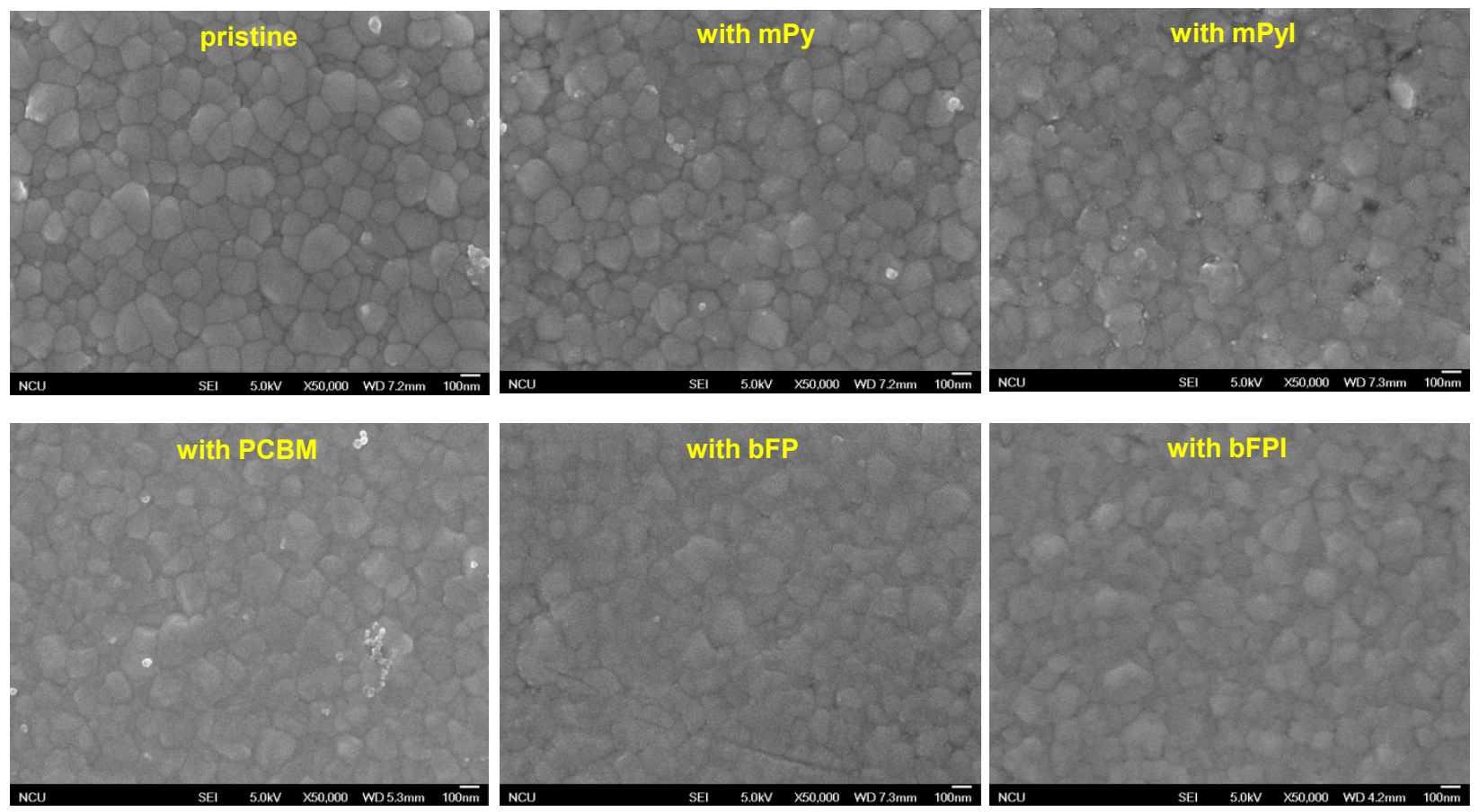

Figure S4. Top-view SEM images of pristine CsFA perovskite films without any treatment and the CsFA films treated with $\mathrm{mPy}(0.2 \mathrm{mg} / \mathrm{mL}), \mathrm{mPyI}(0.2 \mathrm{mg} / \mathrm{mL})$, PCBM $(0.5 \mathrm{mg} / \mathrm{mL}), b F P$ $(0.5 \mathrm{mg} / \mathrm{mL})$ and bFPI $(0.5 \mathrm{mg} / \mathrm{mL})$ treatment. For all the CsFA perovskite films, the surface morphology was composed of crystals in an average size of $200 \mathrm{~nm}$. 
Table S1. Time resolved photoluminescence characterization of the perovskite films without and with surface modification.

\begin{tabular}{cccccc}
\hline Sample & $\tau_{1}(\mathrm{~ns})$ & Fraction 1 & $\tau_{2}(\mathrm{~ns})$ & Fraction 2 & Average (ns) \\
\hline pristine & 7.4 & $48.9 \%$ & 295 & $51.1 \%$ & 154.4 \\
with mPy & 15.6 & $29.4 \%$ & 378 & $70.6 \%$ & 271.5 \\
with mPyI & 17.3 & $12.2 \%$ & 466 & $87.8 \%$ & 411.3 \\
with PCBM & 6.2 & $47.8 \%$ & 272 & $52.2 \%$ & 144.9 \\
with bFP & 5.6 & $45.4 \%$ & 328 & $54.6 \%$ & 181.6 \\
with bFPI & 4.1 & $43.9 \%$ & 342 & $56.1 \%$ & 193.8 \\
\hline
\end{tabular}

Note: The decay is fitted with bimolecular model: $I(\mathrm{t})=I_{0}+A_{1} \exp \left(-{ }^{t} / \tau_{1}\right)+A_{2} \exp \left(-{ }^{t} / \tau_{2}\right.$ ), ( $\tau_{1}$ and $\tau_{2}$ give the fast and slow decay time constant, $A_{1}$ and $A_{2}$ are fractions of the decay processes. Average time is calculated: $\tau=\alpha_{1} \tau_{1}+\alpha_{2} \tau_{2}, \alpha_{i}={ }^{A_{i}} \tau_{i} / \sum A_{i} \tau_{i}$.

For pristine perovskite film, the shorter lifetime originates from the high trap density related to the crystal surface conditions, in which $\tau_{1}$ was assigned as a decay component closely related to non-radiative recombination by defects. The longer lifetime represents the carrier transportation having fewer defects, in which $\tau_{2}$ as a component of radiative recombination. Similarly, we can also analysis the PL lifetime of mPyI-treated CsFA film using the same model. The sample treated with mPyI can effectively interact with both charged defects through ionic bonding, which is consistent with strongly suppressed non-radiative recombination (the longer $\tau_{1}$ ); also the longer $\tau_{2}$ component suggests an improved quality of perovskite film. However, in the case of bFPI modification, ionic fullerenes can also work as a charge acceptor. Thus, we observed decreased $\tau_{1}$ from $7.4 \mathrm{~ns}$ (pristine) to $4.1 \mathrm{~ns}$ upon the treatment of bFPI. We consider the fast decay process to be the result of carrier extraction by the bFPI layers, and the slow decay process to be the result of radiative decay. It is noteworthy that ultra-thin bFPI layer can only play limited contributions on the charge transfer. Consequently, the weight fraction of fast decay decreased and the lifetime of fast decay decreased. Meanwhile, bFPI can also effectively passivate both types of charged defects at perovskite surface. 

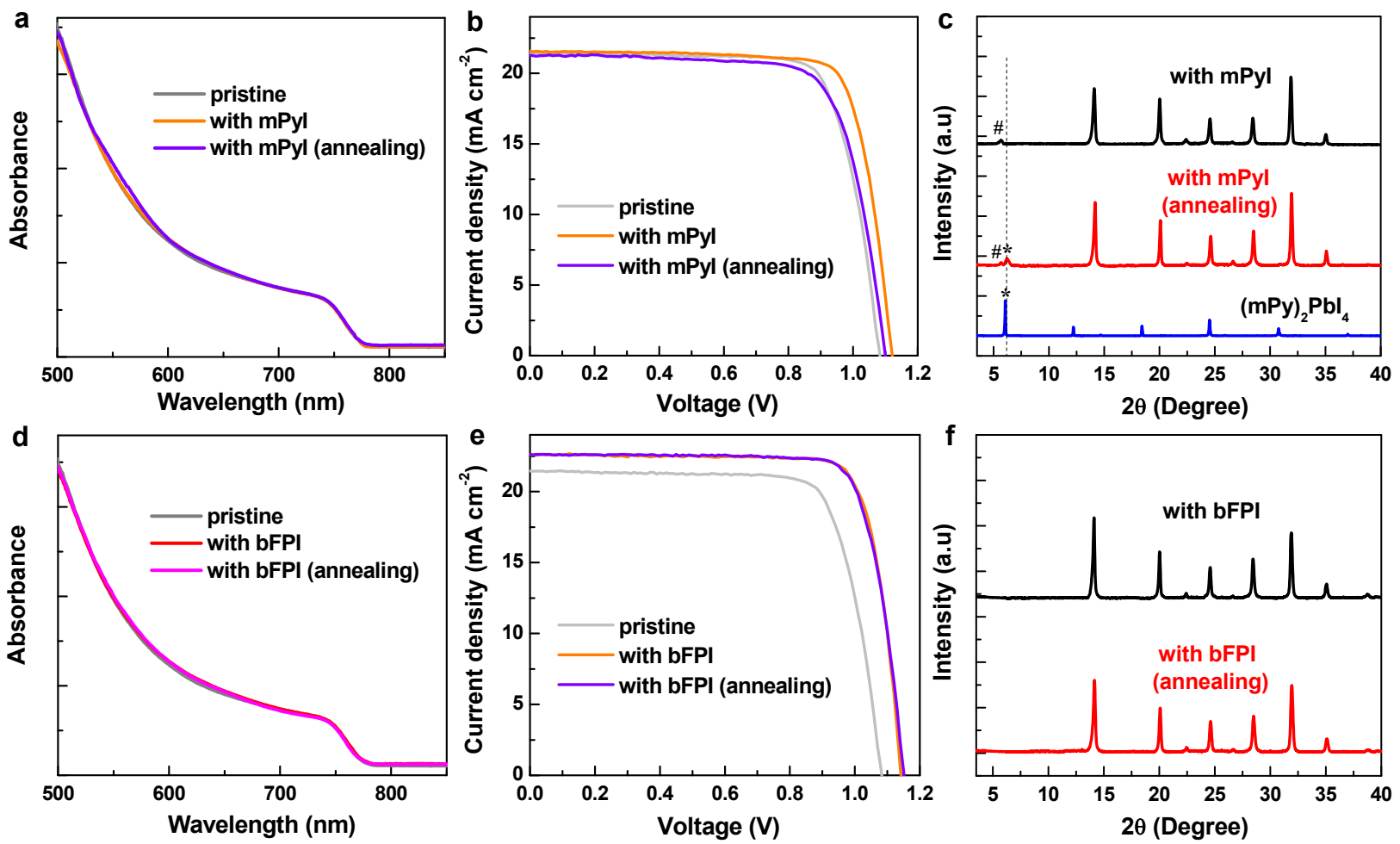

Figure S5. (a) UV-vis absorption spectra, (b) $J-V$ curves of pristine and mPyI-treated CsFA perovskite films, followed with and without thermal annealing $\left(100{ }^{\circ} \mathrm{C}\right.$ for $\left.10 \mathrm{~min}\right)$ after spincoating. (c) XRD patterns of mPyI-treated CsFA perovskite films before and after thermal annealing. The diffraction pattern of the $\left(\mathrm{mPy}_{2} \mathrm{PbI}_{4}\right.$ film is also provided. (d) $\mathrm{UV}$-vis absorption spectra, (e) $J-V$ curves of pristine and bFPI-treated CsFA perovskite films, followed with and without thermal annealing $\left(100^{\circ} \mathrm{C}\right.$ for $\left.10 \mathrm{~min}\right)$ after spin-coating. (f) XRD patterns bFPI-treated CsFA perovskite films before and after thermal annealing. To present a better contrast, highly concentrated mPyI (4 mg ml-1) and bFPI $\left(1.5 \mathrm{mg} \mathrm{ml}^{-1}\right.$, saturated solubility) solutions were used for surface treatment in XRD characterization.

Note: Despite the great advantages of mPyI, there is concern about the conversion of 3D perovskite surface to a layered phase due to the low formation energy. The concern about $2 \mathrm{D}$ perovskite conversion is supported by the absorbance shoulder shown in the UV-vis spectra and related performance after annealing. Besides, the performance of mPyI-treated device with longterm annealing showed inferior performance compared with the control device. In fact, there have been many reports that mixing a certain amount of long alkyl ammonium halides in a perovskite precursor solution easily creates a $3 \mathrm{D} / 2 \mathrm{D}$ mixed hybrid structure, due to low formation energy of the $2 \mathrm{D}$ structure than that of the 3D. However, the device with bFPI treatment was processed with high temperatures annealing $\left(100{ }^{\circ} \mathrm{C}\right.$ for $\left.10 \mathrm{~min}\right)$ after spin-cast and no device performance degradation was found after thermal annealing. We further characterized the XRD of the CsFA films with surface treatment under different conditions. For mPyI-treated perovskite with thermal annealing, the diffraction of mPyI phase is reduced and partially converted into $(\mathrm{mPy})_{2} \mathrm{PbI}_{4}$. This founding is similar with previous works that $3 \mathrm{D}$ perovskite can be easily converted into $2 \mathrm{D}$ by post-treatment of ammonium salts. On the contrary, unlike the case of mPyI treatment, the formation of $(\mathrm{bFP})_{2} \mathrm{PbI}_{4}$ phase is negligible during this post-treatment process under $100^{\circ} \mathrm{C}$ annealing. 
Table S2. Time resolved photoluminescence characterization of the quenched $\mathrm{CsFA} / \mathrm{C}_{60}$ films without and with interfacial passivation.

\begin{tabular}{ccccccc}
\hline Sample & $\tau_{1}(\mathrm{~ns})$ & Fraction 1 & $\tau_{2}(\mathrm{~ns})$ & Fraction 2 & Average $(\mathrm{ns})$ & $\begin{array}{c}\text { Diffusion } \\
\text { Length }(\mu \mathrm{m})\end{array}$ \\
\hline pristine & 8.9 & $68.5 \%$ & 99.7 & $31.5 \%$ & 37.5 & $\sim 0.7$ \\
with mPy & 9.2 & $60.7 \%$ & 125.1 & $39.3 \%$ & 54.8 & $\sim 0.7$ \\
with mPyI & 5.9 & $70.4 \%$ & 82.4 & $29.6 \%$ & 28.6 & $\sim 1.3$ \\
with PCBM & 5.0 & $82.1 \%$ & 72.6 & $17.9 \%$ & 17.1 & $\sim 1.0$ \\
with bFP & 3.4 & $84.6 \%$ & 46.3 & $15.4 \%$ & 10.0 & $\sim 1.5$ \\
with bFPI & 3.1 & $90.8 \%$ & 40.2 & $9.2 \%$ & 6.5 & $\sim 1.9$ \\
\hline
\end{tabular}

Note: Using the fitted photoluminescence lifetime without $(\tau)$ and with $\left(\tau_{\mathrm{q}}\right)$ the presence of quencher, charge diffusion length $\left(L_{\mathrm{D}}\right)$ can be estimated by the equation:

$$
L_{D} \approx \frac{2 L}{\pi} \sqrt{2\left(\frac{\tau}{\tau_{q}}-1\right)}
$$

, where the $L$ stand for the film thickness $(400 \mathrm{~nm})$.
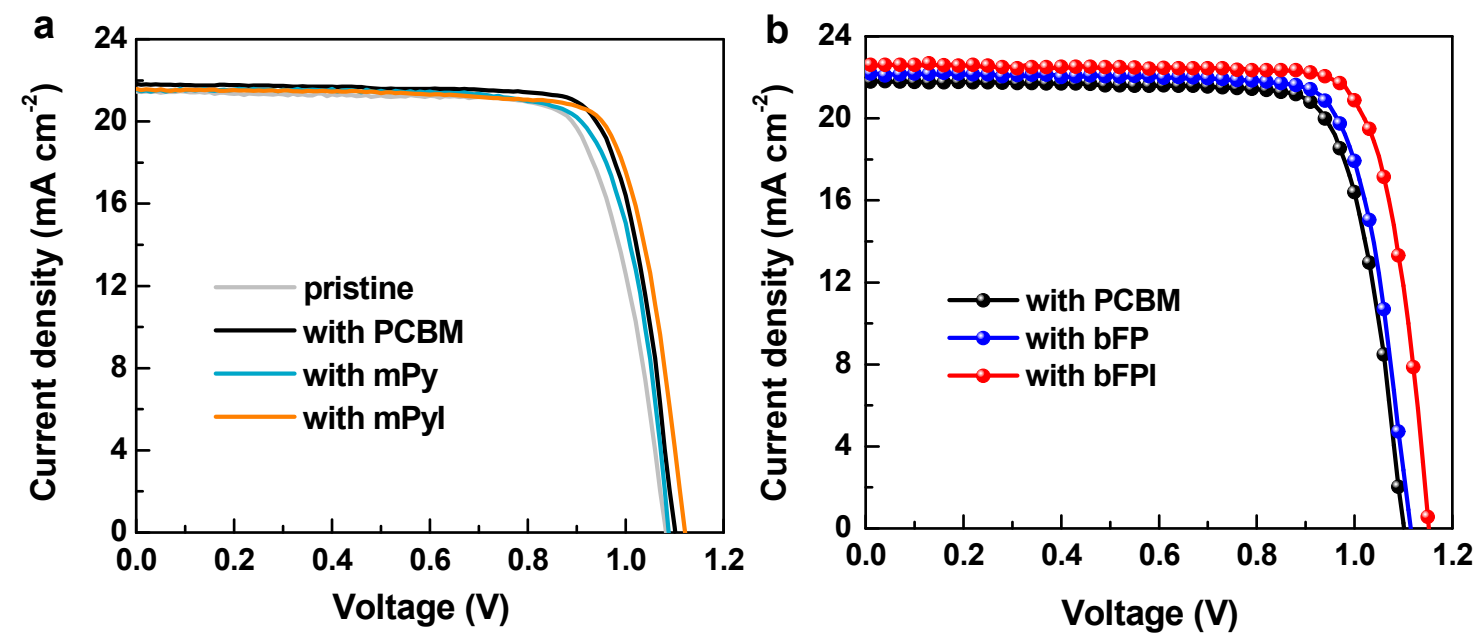

Figure S6. $J-V$ characteristics of optimized best CsFA PSCs under AM 1.5G illumination a) with pristine, with PCBM-treated, mPy-treated and mPyI-treated perovskite surface; b) with PCBMtreated, bFP-treated and bFPI-treated perovskite surface. 
Table S3. Performance of champion CsFA device processed from different interfacial materials under reverse direction.

\begin{tabular}{cccccc}
\hline Materials & $J_{\mathrm{SC}}\left(\mathrm{mA} \mathrm{cm}^{-2}\right)$ & $V_{\mathrm{OC}}(\mathrm{V})$ & FF & PCE $(\%)$ & ${\text { Average PCE }(\%)^{\mathrm{a}}}^{\text {pristine }}$ \\
\hline with PCBM & 21.44 & 1.08 & 0.771 & 17.85 & $17.02 \pm 0.57$ \\
with mPy & 21.82 & 1.10 & 0.798 & 19.15 & $18.32 \pm 0.41$ \\
with mPyI & 21.51 & 1.09 & 0.782 & 18.31 & $17.50 \pm 0.52$ \\
with bFP & 22.14 & 1.12 & 0.799 & 19.24 & $18.33 \pm 0.44$ \\
with bFPI & 22.58 & 1.15 & 0.813 & 21.11 & $20.38 \pm 0.43$ \\
\hline
\end{tabular}

a)The statistical data of device parameters from a set of 40 cells.

Table S4. Summary of MA-free PSCs with high efficiencies under simulated solar light condition (AM 1.5).

\begin{tabular}{|c|c|c|c|c|c|c|}
\hline Perovskite Materials & Device Structure & $\begin{array}{c}J_{\mathrm{SC}}(\mathrm{mA} \mathrm{cm}- \\
2)\end{array}$ & $V_{\mathrm{OC}}(\mathrm{V})$ & $\mathrm{FF}$ & $\operatorname{PCE}(\%)^{\mathrm{a}}$ & $\operatorname{PCE}(\%)^{\mathrm{b}}$ \\
\hline $\begin{array}{c}\mathrm{Cs}_{0.17} \mathrm{FA}_{0.83} \mathrm{~Pb}\left(\mathrm{I}_{0.83} \mathrm{Br}_{0.17}\right) \\
3 \\
\text { (bandgap } \sim 1.6 \mathrm{eV})^{\mathrm{c}}\end{array}$ & $\begin{array}{c}\mathrm{FTO} / \mathrm{ZnO} / \mathrm{C}_{60} / \text { perovskite/Spiro- } \\
\mathrm{OMeTAD} / \mathrm{Ag}\end{array}$ & 23.51 & 1.20 & 0.79 & $21.1^{6}$ & 19.7 \\
\hline $\begin{array}{c}\mathrm{Rb}_{0.05} \mathrm{FA}_{0.95} \mathrm{PbI}_{3} \\
\text { (bandgap } 1.53 \mathrm{eV} \text { ) }\end{array}$ & $\begin{array}{c}\mathrm{FTO} / \mathrm{bl}-\mathrm{TiO}_{2} / \mathrm{mp}_{-} \mathrm{TiO}_{2} / \\
\text { perovskite/ Spiro-OMeTAD/Au }\end{array}$ & 23.93 & 1.07 & 0.67 & $17.2^{7}$ & 16.8 \\
\hline $\begin{array}{l}\mathrm{Cs}_{0.20} \mathrm{FA}_{0.80} \mathrm{PbI}_{3}-(\mathrm{Cl}) \\
\text { (bandgap } 1.56 \mathrm{eV})\end{array}$ & $\begin{array}{c}\mathrm{FTO} / \mathrm{bl}-\mathrm{TiO}_{2} / \mathrm{mp}-\mathrm{TiO}_{2} / \\
\text { perovskite/ Spiro-OMeTAD/Au }\end{array}$ & 24.10 & 1.10 & 0.78 & $20.6^{8}$ & 19.9 \\
\hline $\begin{array}{c}\mathrm{BA}_{0.05}\left(\mathrm{Cs}_{0.17} \mathrm{FA}_{0.83}\right)_{0.91} \mathrm{~Pb} \\
\left(\mathrm{I}_{0.8} \mathrm{Br}_{0.2}\right)_{3} \\
\text { (bandgap } 1.61 \mathrm{eV})\end{array}$ & $\begin{array}{l}\mathrm{FTO} / \mathrm{SnO}_{2} / \mathrm{PCBM} / \text { perovskite/ } \\
\text { Spiro-OMeTAD/Ag }\end{array}$ & 22.70 & 1.14 & 0.80 & $20.6^{9}$ & 19.5 \\
\hline $\begin{array}{c}\left(\mathrm{Cs}_{0.17} \mathrm{FA}_{0.83}\right) \mathrm{Pb}\left(\mathrm{I}_{0.89} \mathrm{Br}_{0.0}\right. \\
\left.{ }_{8} \mathrm{Cl}_{0.03}\right)_{3} \\
\text { (bandgap } 1.58 \mathrm{eV})\end{array}$ & 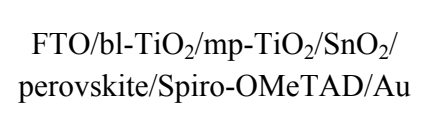 & 23.28 & 1.12 & 0.78 & $20.5^{10}$ & - \\
\hline $\begin{array}{l}\mathrm{Rb}_{0.05} \mathrm{Cs}_{0.10} \mathrm{FAPbI} \mathrm{F}_{3} \\
\text { (bandgap } 1.53 \mathrm{eV} \text { ) }\end{array}$ & $\begin{array}{c}\mathrm{FTO} / \mathrm{SnO}_{2} / \mathrm{PCBM}-\mathrm{PMMA} / \\
\text { perovskite/Spiro-OMeTAD/Au }\end{array}$ & 25.06 & 1.08 & 0.76 & $20.4^{11}$ & 20.3 \\
\hline $\begin{array}{l}\mathrm{Cs}_{0.15} \mathrm{FA}_{0.85} \mathrm{~Pb}\left(\mathrm{I}_{0.9} \mathrm{Br}_{0.1}\right)_{3} \\
\text { (bandgap } 1.58 \mathrm{eV} \text { ) }\end{array}$ & $\begin{array}{c}\mathrm{FTO} / \mathrm{bl}-\mathrm{TiO}_{2} / \text { perovskite} / \mathrm{PbS} / \\
\text { spiro-OMeTAD/Au }\end{array}$ & 23.06 & 1.15 & 0.80 & $21.1^{12}$ & 20.3 \\
\hline $\begin{array}{l}\left(\mathrm{CsPbBr}_{3}\right)_{0.06}\left(\mathrm{FAPbI}_{3}\right)_{0.94} \\
\quad(\text { bandgap } 1.55 \mathrm{eV})\end{array}$ & $\begin{array}{c}\mathrm{FTO} / \mathrm{bl}-\mathrm{TiO}_{2} / \mathrm{mp}-\mathrm{TiO}_{2} / \\
\text { perovskite/ Spiro-OMeTAD/Au }\end{array}$ & 24.52 & 1.15 & 0.78 & $21.8^{13}$ & 21.1 \\
\hline $\begin{array}{c}\mathrm{FAPbI}_{3}: \mathrm{xMDACl}_{2}(\mathrm{x}= \\
3.8 \mathrm{~mol} \%) \\
\text { (bandgap } 1.47 \mathrm{eV})\end{array}$ & $\begin{array}{c}\mathrm{FTO} / \mathrm{bl}-\mathrm{TiO}_{2} / \mathrm{mp}-\mathrm{TiO}_{2} / \\
\text { perovskite/ Spiro-OMeTAD/Au }\end{array}$ & 26.50 & 1.14 & 0.92 & $24.7^{14}$ & 23.7 \\
\hline $\begin{array}{c}\left(\mathrm{Cs}_{0.05} \mathrm{FA}_{0.95}\right) \mathrm{PbI}_{3} \\
\text { (bandgap } \sim 1.5 \mathrm{eV} \text { ) }\end{array}$ & $\begin{array}{c}\text { ITO/PTAA/PFN-P2/perovskite/ } \\
\mathrm{LiF} / \mathrm{C}_{60} / \mathrm{BCP} / \mathrm{Cu} \text { (inverted) }\end{array}$ & 25.10 & 1.05 & 0.75 & $19.8^{15}$ & - \\
\hline $\begin{array}{c}\left(\mathrm{Cs}_{0.15} \mathrm{FA}_{0.85}\right) \mathrm{Pb}\left(\mathrm{I}_{0.9} \mathrm{Br}_{0.1}\right) \\
3 \\
\text { (bandgap } \sim 1.58 \mathrm{eV})\end{array}$ & $\begin{array}{l}\text { ITO/PTAA/PFN-P2/perovskite/ } \\
\mathrm{LiF} / \mathrm{C}_{60} / \mathrm{BCP} / \mathrm{Cu} \text { (inverted) }\end{array}$ & 23.19 & 1.11 & 0.80 & $20.7^{16}$ & 20.2 \\
\hline $\begin{array}{c}\left(\mathrm{Cs}_{0.17} \mathrm{FA}_{0.83}\right) \mathrm{Pb}\left(\mathrm{I}_{0.8} \mathrm{Br}_{0.2}\right) \\
3 \\
\text { (bandgap } 1.61 \mathrm{eV})\end{array}$ & $\begin{array}{l}\text { ITO/PTAA/PFN-Br/perovskite/ } \\
\text { bFPI/ } \mathrm{C}_{60} / \mathrm{BCP} / \mathrm{Cu} \text { (inverted) }\end{array}$ & 22.58 & 1.15 & 0.81 & $\begin{array}{c}21.1 \\
\text { (this work) }\end{array}$ & 20.8 \\
\hline
\end{tabular}

${ }^{\mathrm{a}}$ Measured from $\mathrm{J}-\mathrm{V}$ curve; ${ }^{\mathrm{b}}$ measured from steady-state power output. ${ }^{\mathrm{c}}$ The bandgap values are quoted from references and some values are not explicitly stated. In such case, we extracted the optical bandgap values from corresponding absorption spectra. 


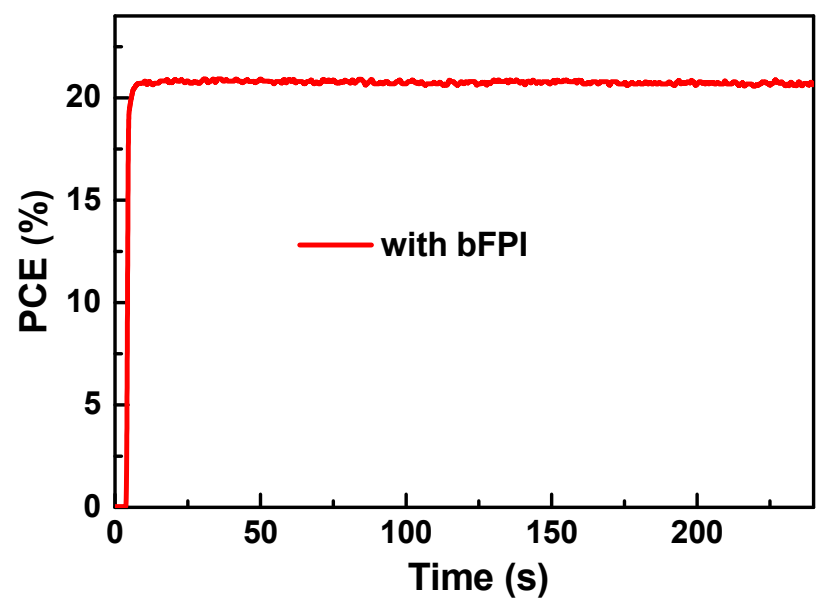

Figure S7. The steady-state power output for best device with bFPI treatment. The maximum voltage, current density and the steady-state output for the bFPI-treated devices are $0.97 \mathrm{~V}, 21.4$ $\mathrm{mA} / \mathrm{cm}^{2}$ and $20.8 \%$, respectively.

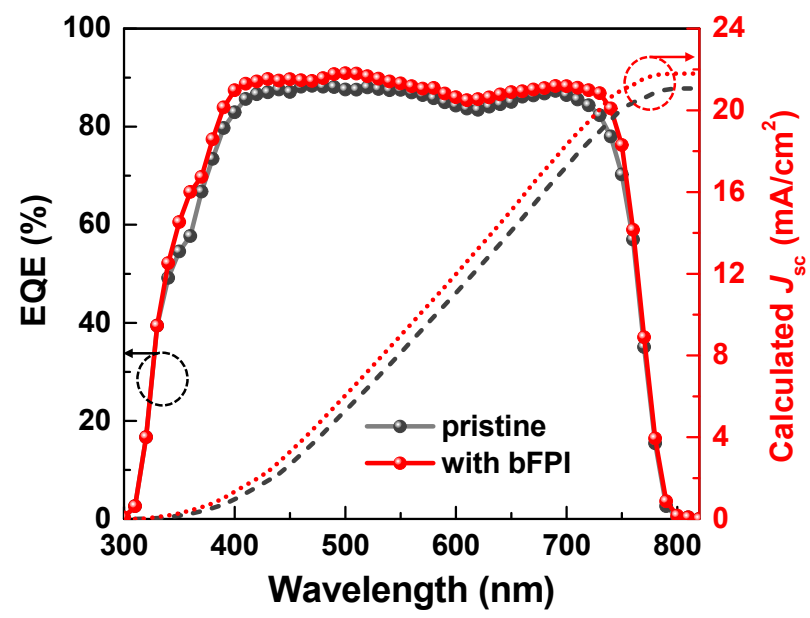

Figure S8. EQE spectra and integrated photo-current of champion pristine and bFPI-treated CsFA devices. 


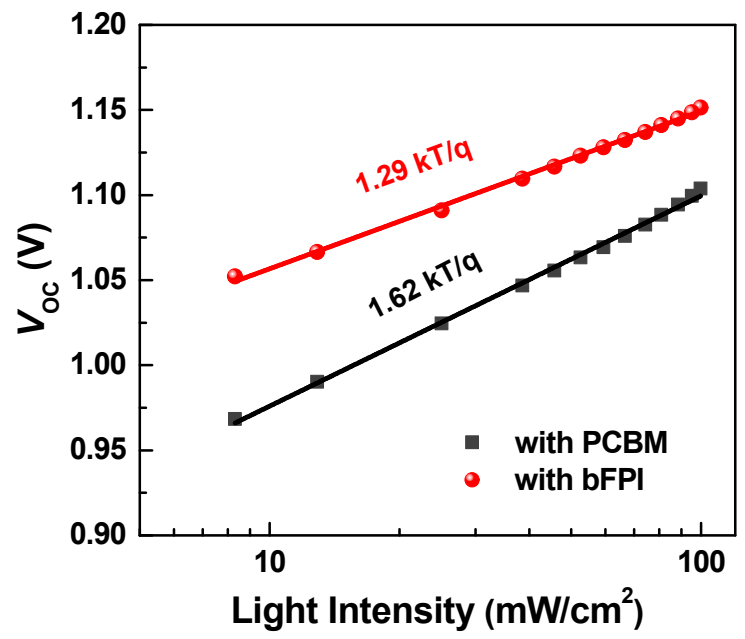

Figure S9. $V_{\mathrm{OC}}$ versus light intensity for the CsFA PSCs with treatment of PCBM and bFPI. A natural logarithmic relationship between $V_{\mathrm{OC}}$ and light intensity yields a slope of $n=\frac{q d V_{O C}}{k T d \ln (\varphi)}$, where $n$ is the ideality factor, $k$ is the Boltzmann's constant, $T$ is the temperature, and $q$ is an elementary charge, according to the Shockley-Read-Hall theory.

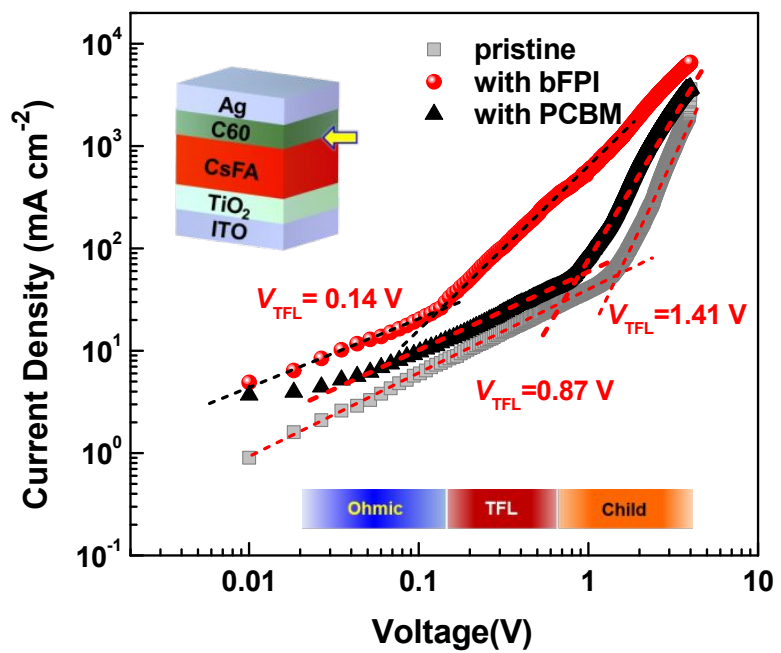

Figure S10. Dark $J-V$ of the electron-only devices of device without and with modification as determined by the space-charge-limited current (SCLC) method, displaying $V_{\text {TFL }}$ kink point. The trap density $N_{\text {trap }}$ is determined by the equation: $V_{\mathrm{TFL}}=\mathrm{e} N_{\text {trap }} L^{2} /\left(2 \varepsilon \varepsilon_{0}\right)$, where $V_{\mathrm{TFL}}$ is trap-filled limit voltage, $L$ is the thickness of CsFA film, $\varepsilon$ is the relative dielectric constant of perovskite, and $\varepsilon_{0}$ is the vacuum permittivity. The trap density of pristine device is calculated to be $7.39 \times$ $10^{16} \mathrm{~cm}^{-3}$, and is remarkably decreased to $4.88 \times 10^{16}$ and $9.24 \times 10^{15} \mathrm{~cm}^{3}$ for devices modified with PCBM control and bFPI, respectively. 

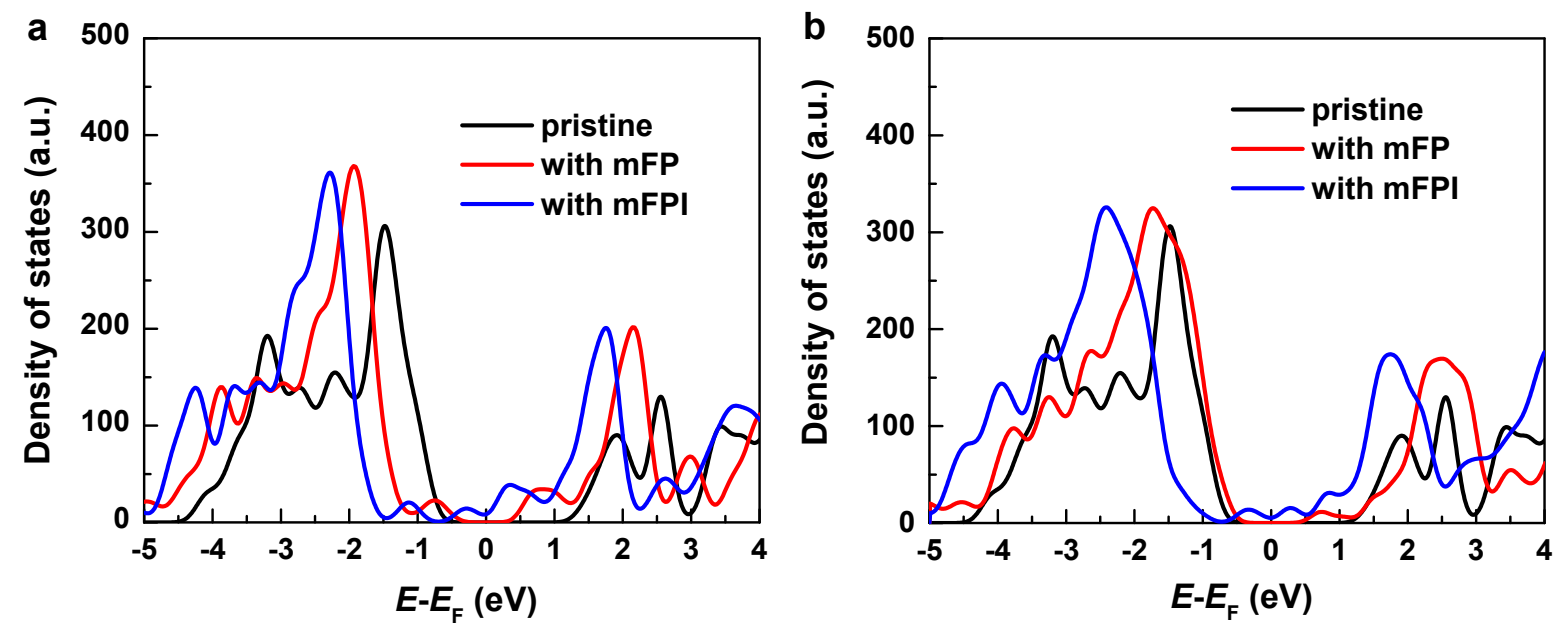

Figure S11. (a) DFT-calculated total density of states (DOS) for pristine $\mathrm{FAPbI}_{3}$ surface $\left(\mathrm{PbI}_{2}\right.$ termination) without and with passivation. Fermi level is set to be zero. (b) DFT-calculated total density of states (DOS) for pristine $\mathrm{FAPbI}_{3}$ surface (FAI termination) without and with monosubstituted fullerene derivates ( $\mathrm{mFPI}$ and $\mathrm{mFP}$ ) passivation. Fermi level of pristine perovskite is set to be zero. 

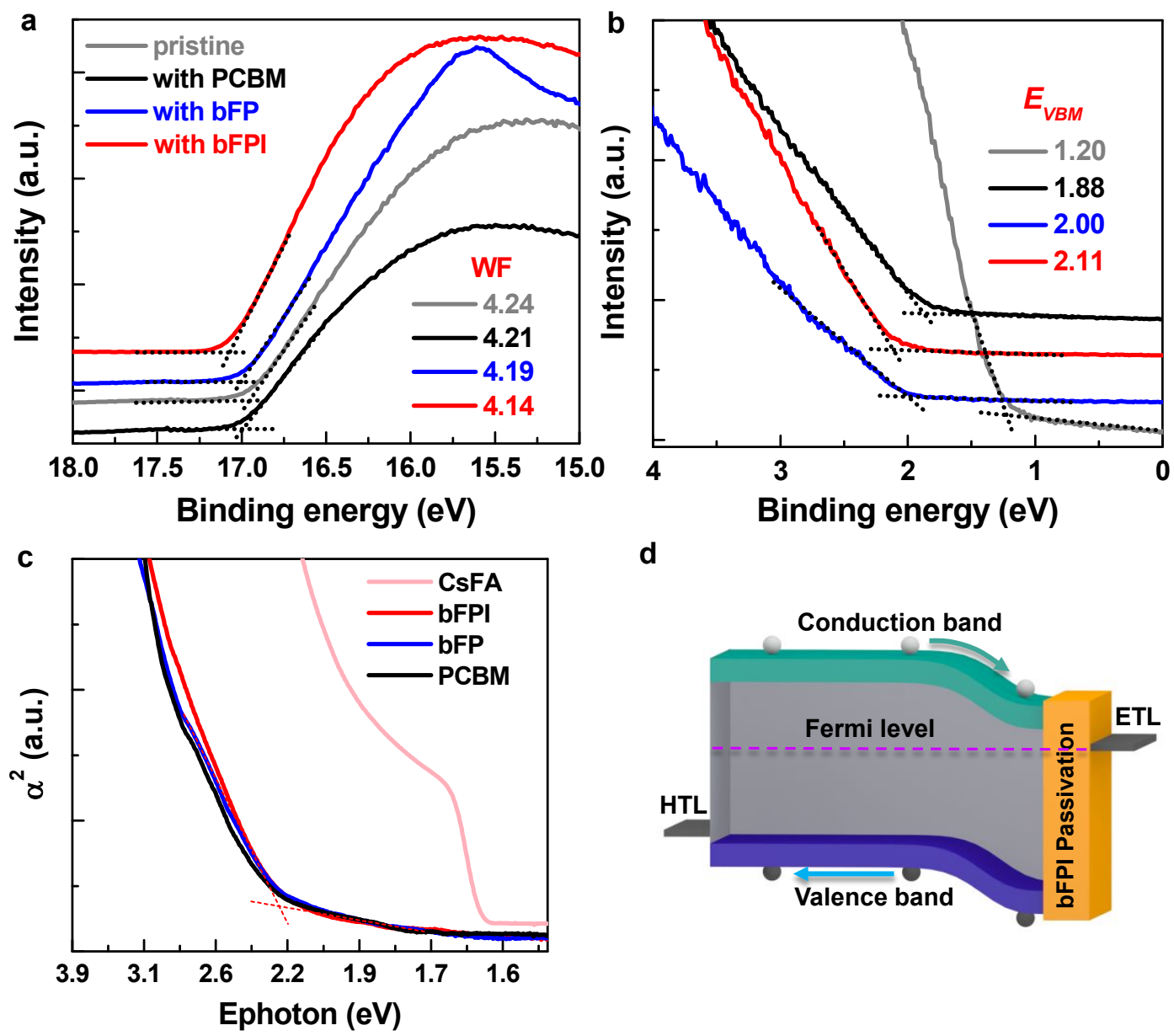

d

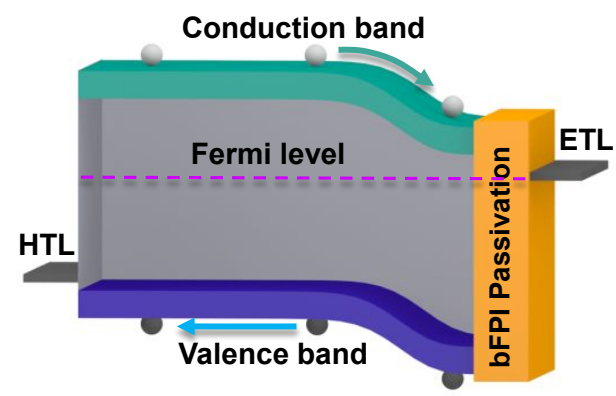

Figure S12. (a) UPS spectra around the secondary electron cut-off of pristine CsFA perovskite before and after ultra-thin bFPI, bFP and PCBM treatment. (b) UPS spectra in the valence band (VB) region. (c) Tauc-plot of CsFA perovskite, bFP, bFPI and PCBM. (d) Scheme of bandbending induced passivation. 

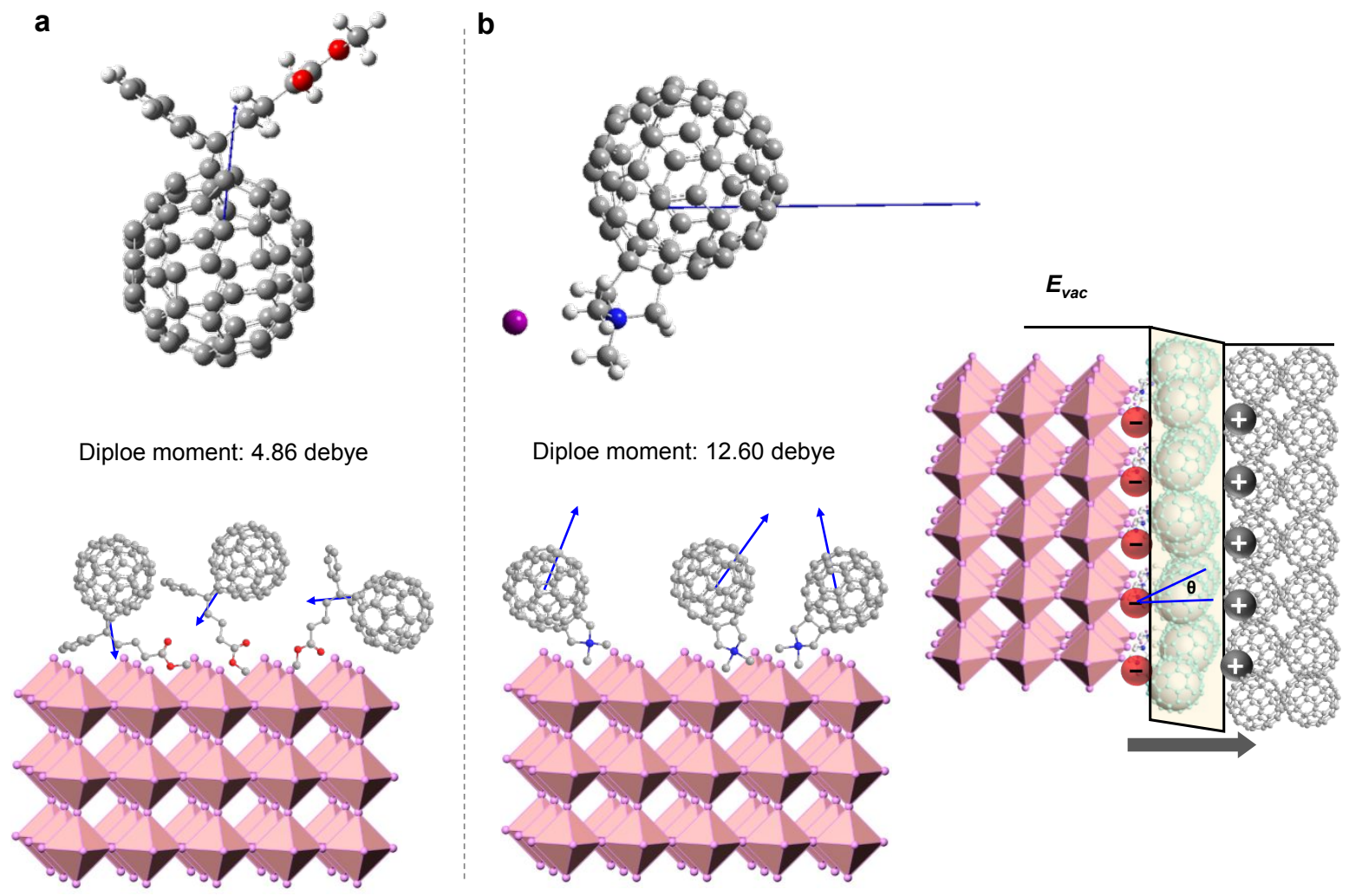

Figure S13. Molecular permanent dipole moment based on DFT calculation (a) PCBM and (b) ionic fullerene (mono-substituted fullerene derivates for simplification), and orientation illustration of the fullerene molecules on the surface of CsFA film. The blue arrows represent permanent dipole moments with respect to the passivator molecules. Scheme of energy level alignment at the bFPI-treated interface is also provided.

Note: These differences may be rationalized by considering the dipole moment at the interface induced by varying molecule orientation of fullerene moiety at the interface. Previous reported demonstrated that the strong interaction strength between perovskite surface sites and the zwitterion group would contribute to a preferred dipole orientation. ${ }^{17}$ The assembly of bFPI forms a dipole interlayer with its negative end pointed towards perovskite and positive end pointed outside (blue arrow). 

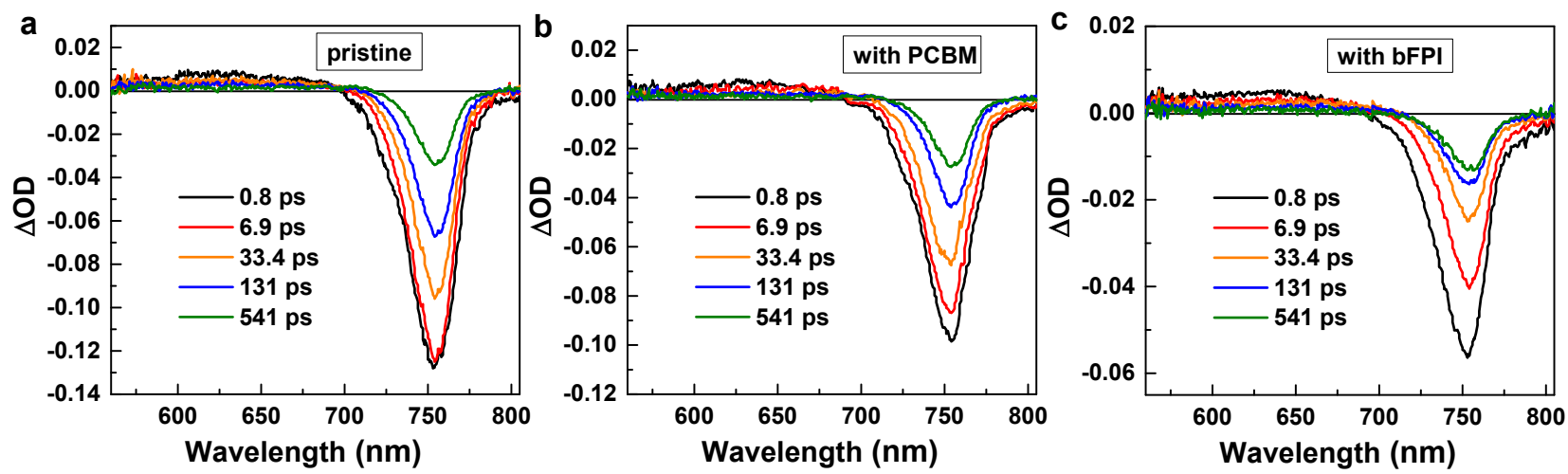

Figure S14. fs-TA spectra of the $\mathrm{CsFA} / \mathrm{C}_{60}$ samples with different interfacial modification layers at various pump-probe time delays. The excitation wavelength was $520 \mathrm{~nm}$, with fluence of 27 $\mu \mathrm{J} \mathrm{cm}^{-2}$. The peak around $750 \mathrm{~nm}$ is assigned to ground-state bleaching (GSB) resulting from band edge transition.
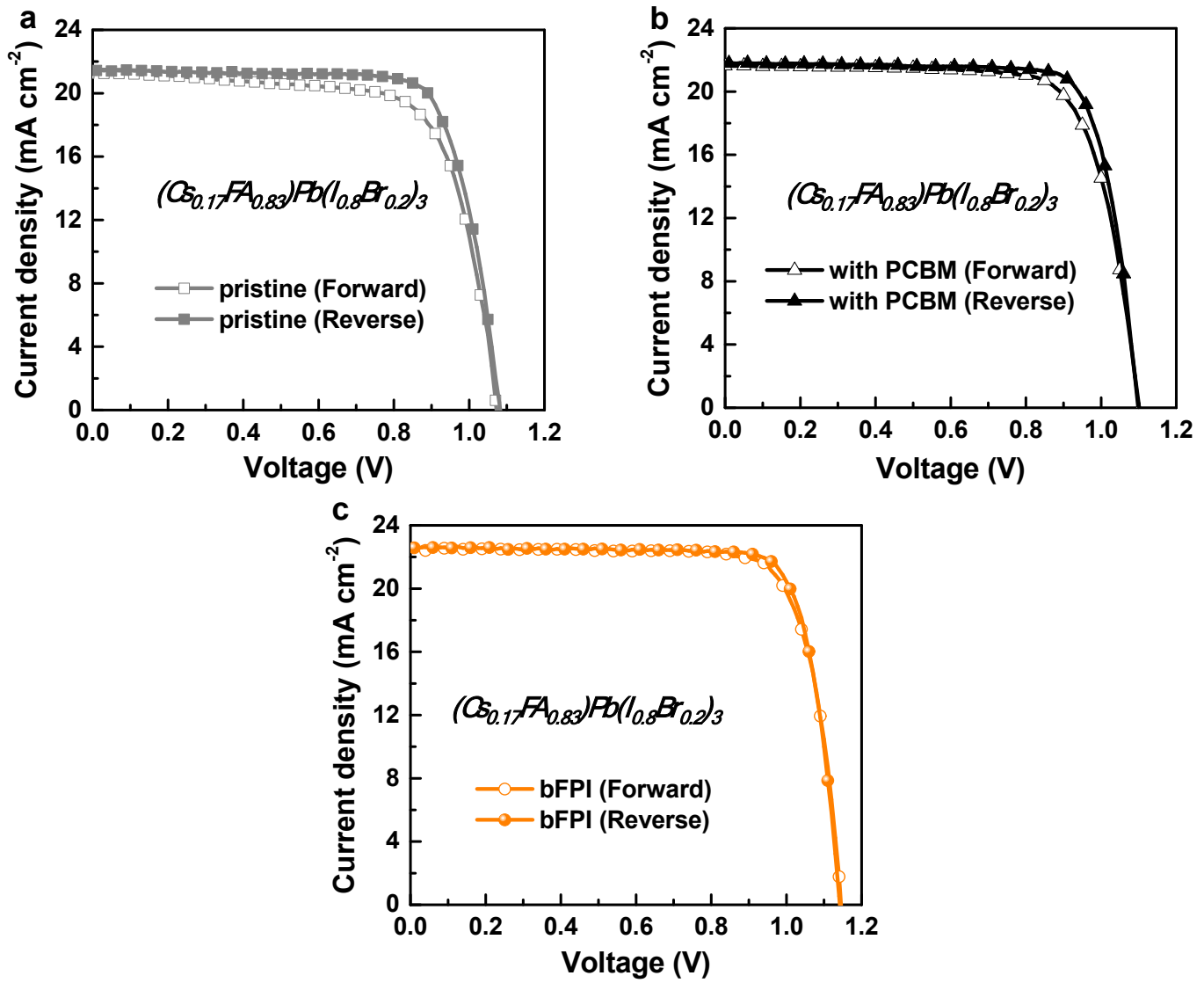

Figure S15. The $J-V$ curve from the reverse scan (from $V$ oc to $J$ sc) and forward scan (from $J$ sc to $V$ oc) for the champion (a) pristine, (b) PCBM-treated and (c) bFPI-treated devices under 1 Sun condition. 
Table S5. Performance of champion CsFA device processed from different interfacial materials under different scan directions.

\begin{tabular}{ccccccc}
\hline Materials & Scan Direction & $J_{\mathrm{SC}}\left(\mathrm{mA} \mathrm{cm}^{-2}\right)$ & $V_{\mathrm{OC}}(\mathrm{V})$ & FF & PCE $(\%)$ & hysteresis index $(\mathrm{HI})^{\mathrm{a}}$ \\
\hline pristine & Forward & 21.28 & 1.07 & 0.715 & 16.28 & 0.072 \\
pristine & Reverse & 21.44 & 1.08 & 0.771 & 17.85 & \\
with bFPI & Forward & 22.51 & 1.15 & 0.796 & 20.61 & \multirow{2}{*}{0.014} \\
with bFPI & Reverse & 22.58 & 1.15 & 0.813 & 21.11 & \\
with PCBM & Forward & 20.63 & 1.10 & 0.749 & 17.81 & \multirow{2}{*}{0.046} \\
with PCBM & Reverse & 21.82 & 1.10 & 0.798 & 19.15 & \\
\hline
\end{tabular}

a) The definition of hysteresis index $(\mathrm{HI})$ value is $\left[\mathrm{HI}=1-J_{\mathrm{FS}}\left(0.8 V_{\mathrm{OC}}\right) / J_{\mathrm{RS}}\left(0.8 V_{\mathrm{OC}}\right)\right]$, where $J_{\mathrm{RS}}\left(0.8 V_{\mathrm{OC}}\right)$ and $J_{\mathrm{FS}}\left(0.8 V_{\mathrm{OC}}\right)$ stand for photocurrent density at $80 \%$ of $V_{\mathrm{OC}}$ for the reverse and forward sweep, respectively.

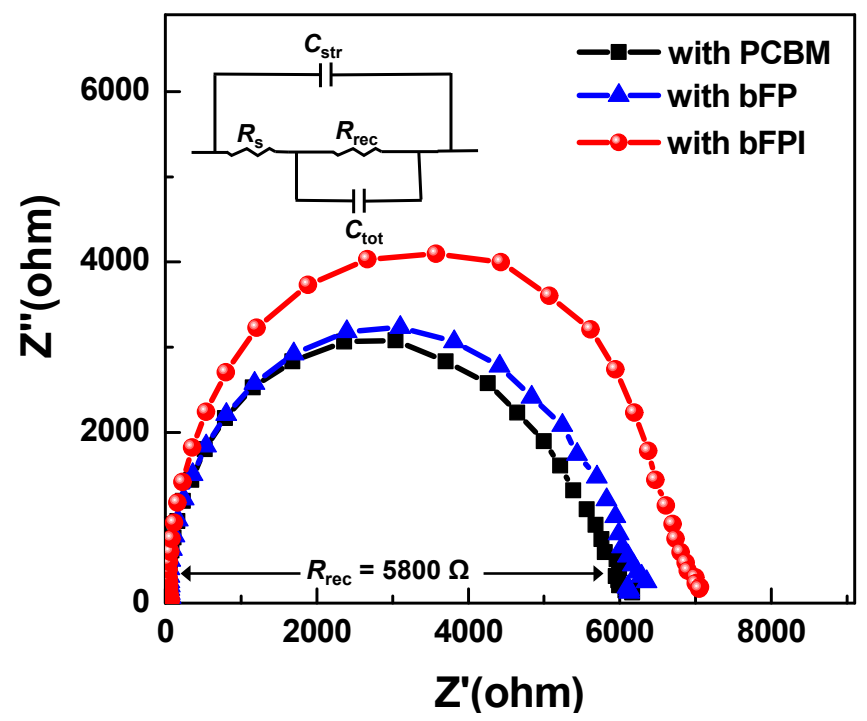

Figure S16. Nyquist plots of CsFA PSCs with surface modification of various fullerene derivates. Electrochemical impedance spectroscopy (EIS) measurements were performed at a bias of $0.8 \mathrm{~V}$ under illumination, sweeping from $100 \mathrm{~Hz}$ to $1 \mathrm{MHz}$. As shown in the inset image, the response for our planar p-i-n solar cells can be fitted a single semicircle. Equivalent circuit of the planar inverted solar cell with elements representing the cell capacitance, $C_{\text {tot }}$, recombination resistance, $R_{\mathrm{rec}}$, series resistance, $R_{\mathrm{s}}$, and the stray capacitance $C_{\mathrm{str}}$.

Note: We used this equivalent circuit containing a mid-frequency arc, to fit the experimental data, in which the radii of the impedance semicircle relate to the $R_{\text {rec }}$ of the PSCs. As shown in modified Figure S16, the bFPI-treated PSC exhibits a much larger recombination resistance $(6940 \Omega)$ than that of the control PCBM-device $(5800 \Omega)$ and bFP-treated PSC $(6110 \Omega)$, which indicates that the bFPI treatment effectively reduces the recombination paths. Herein, the facilitated charge transfer accompanied by the retarded recombination process justifies the $V_{\mathrm{OC}}$ losses and thus improved performance of bFPI-treated PSCs. 


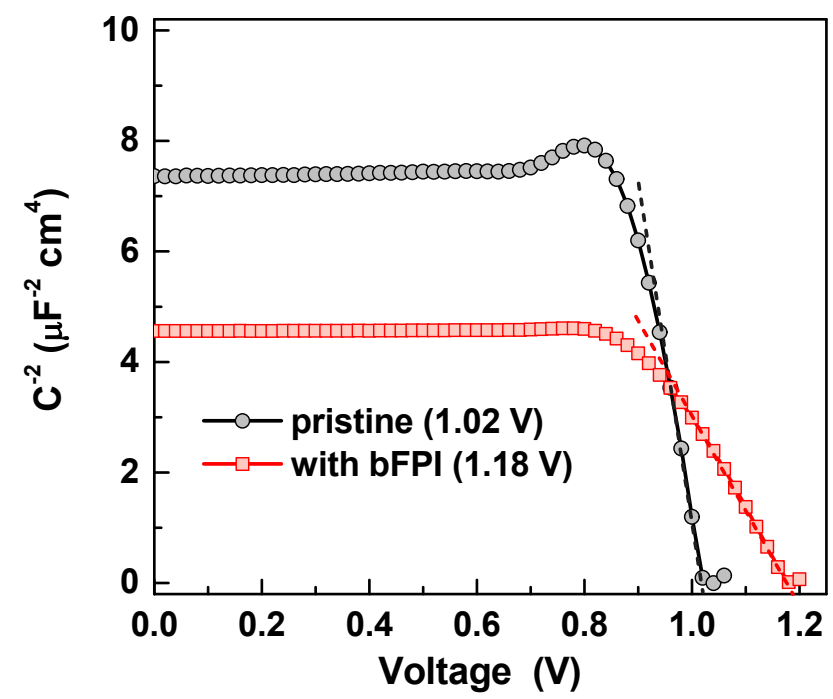

Figure S17. Capacitance-voltage curve plotted according to Mott-Schottky relation for pristine and bFPI-treated devices at $1 \mathrm{kHz}$. These plots directly demonstrate the higher flat-band potential of the modified device compared with the pristine device, which is related to an increase in $V_{\mathrm{OC}}$.

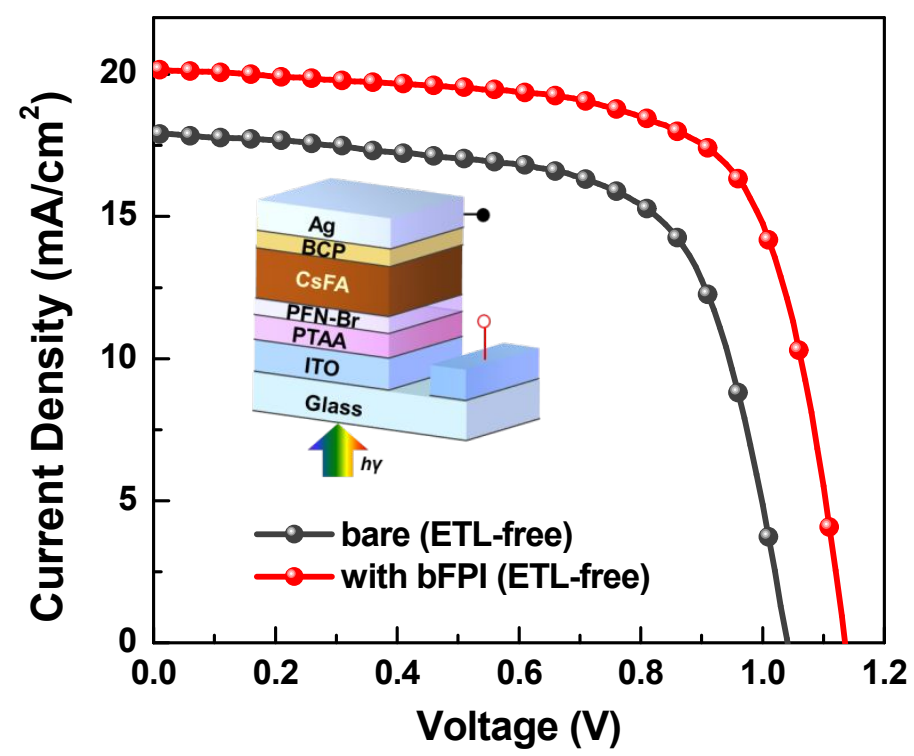

Figure S18. The $J-V$ curves of the studied ETL-free $\left(\mathrm{C}_{60}\right.$-free) device with and without bFPI treatment. The inset shows the device architecture of the ETL-free PSCs. 

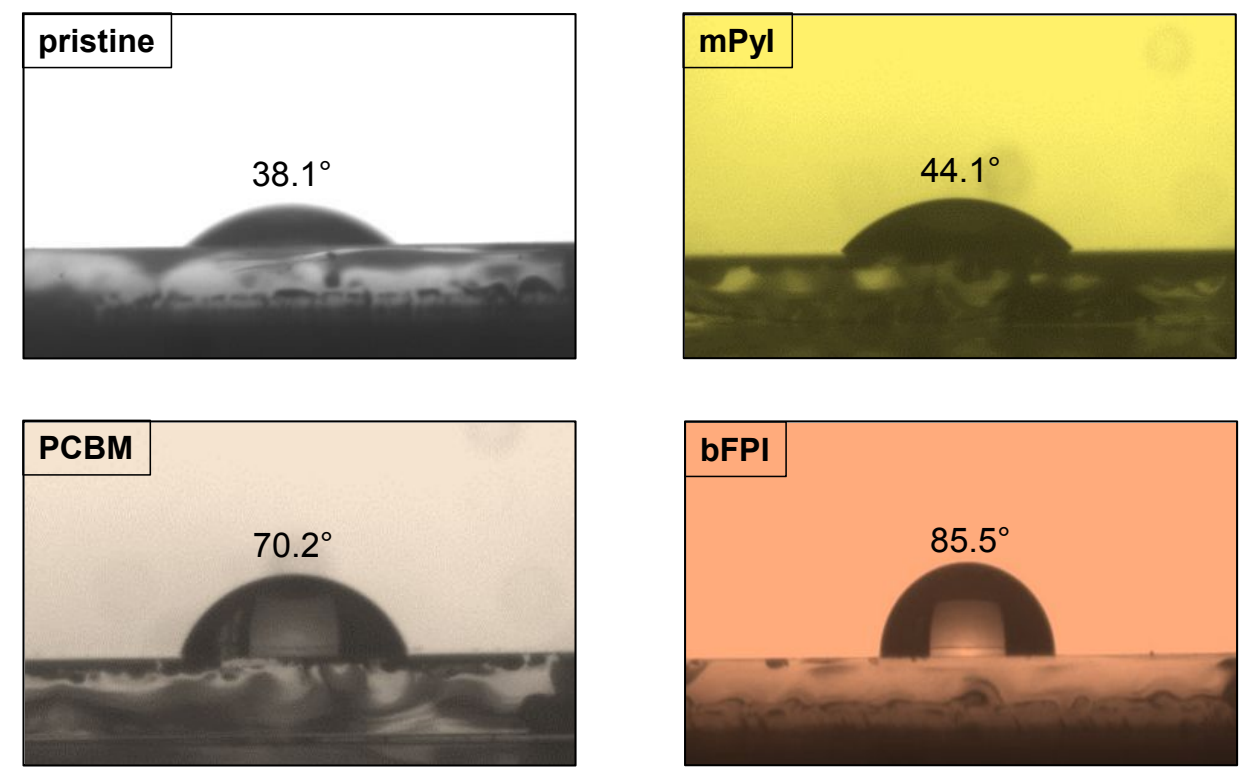

Figure S19. Representative photographs showing the water contact angles of CsFA perovskite films treated with different passivators.

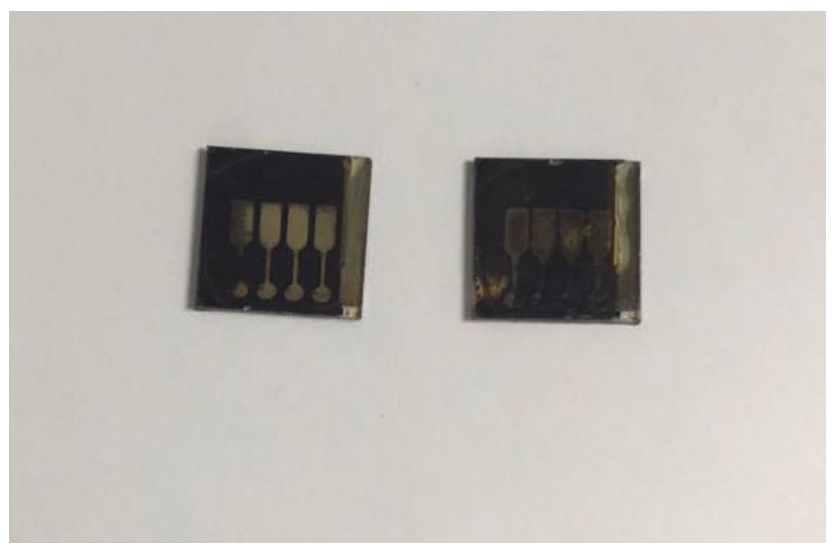

Figure S20. Photographs of the unencapsulated bFPI-treated (left) and pristine (right) devices after one month storage under ambient condition with $50-70 \% \mathrm{RH}$. 

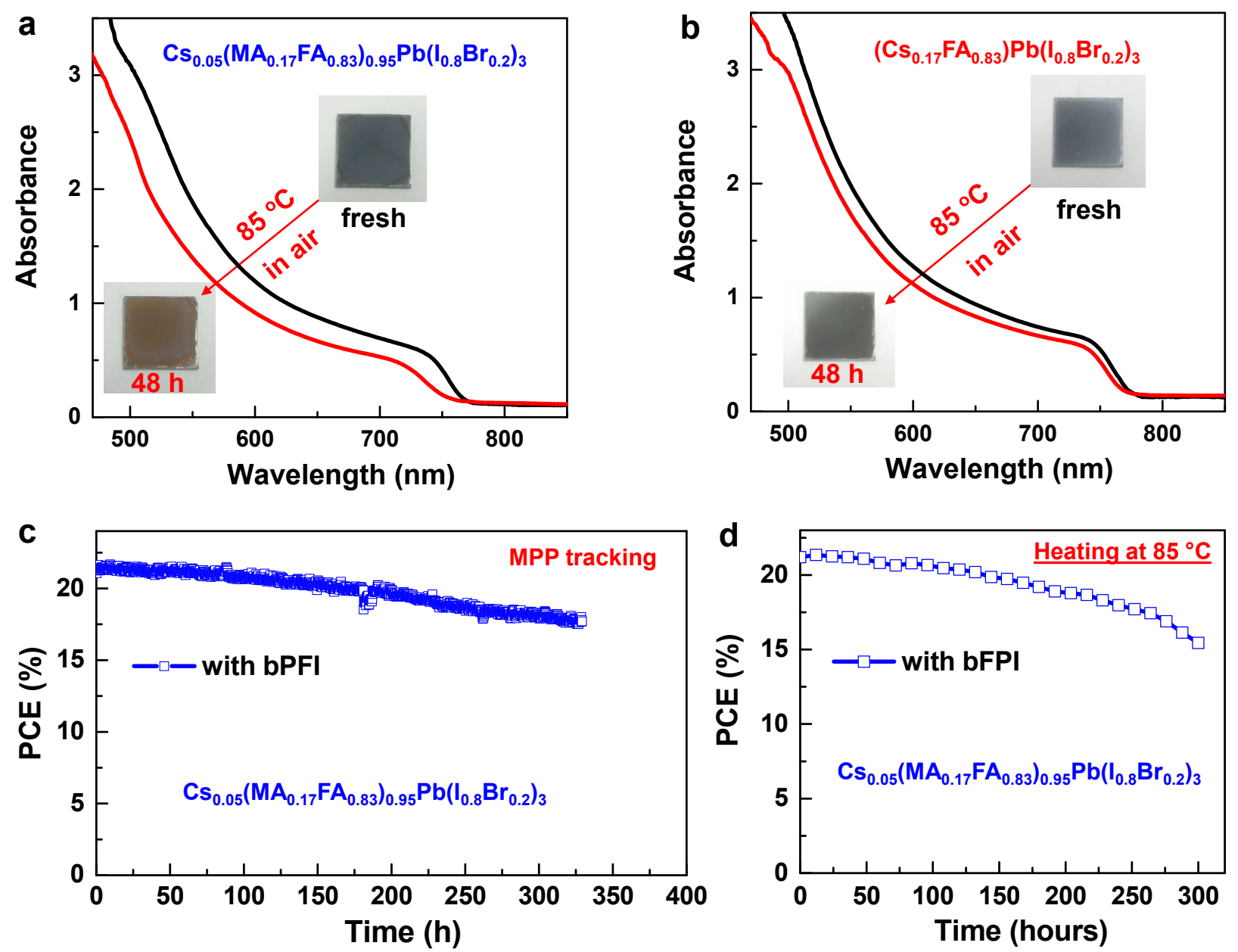

Figure S21. UV-visible absorption of (a) $\mathrm{Cs}_{0.05}\left(\mathrm{MA}_{0.17} \mathrm{FA}_{0.83}\right)_{0.95} \mathrm{~Pb}\left(\mathrm{I}_{0.8} \mathrm{Br}_{0.2}\right)_{3}(\mathrm{CsMAFA})$ and (b) CsFA perovskite films annealed at $85^{\circ} \mathrm{C}$ for 48 hours at ambient condition with $50-70 \% \mathrm{RH}$. The insets show the corresponding optical images. (c) Operational stability measurement of the encapsulated devices based on bFPI-modified CsMAFA perovskite under continuous 1-sun illumination at ambient condition with 50-70\% RH. (d) Aging for $300 \mathrm{~h}$ of a encapsulated bFPImodified devices heated continuously at $85{ }^{\circ} \mathrm{C}$ tracked by PCE measurement at periodic intervals for $12 \mathrm{~h}$.

Note: It is evident from the inset images that the CsMAFA films start degradation after the aggressive thermal testing as evidenced by the decreased absorption spectrum. CsFA on the other hand retains the black color without noticeable degradation, compared with CsMAFA. Moreover, CsMAFA devices rapidly lost $\sim 30 \%$ of their initial PCE after $300 \mathrm{~h}$ of testing. 


\section{References}

1. Bosi, S.; Feruglio, L.; Milic D.; Prato, M. Synthesis and Water Solubility of Novel Fullerene Bisadduct Derivatives. Eur. J. Org. Chem. 2003, 2003 (24), 4741-4747.

2. Kresse, G.; Furthmüller, J. Efficient Iterative Schemes for Ab Initio Total-Energy Calculations Using a Plane-Wave Basis Set. Phys. Rev. B 1996, 54 (16), 11169.

3. Kresse, G.; Joubert, D. From ultrasoft pseudopotentials to the projector augmented-wave method. Phys. Rev. B 1999, 59 (3), 1758.

4. Perdew, J. P.; Burke, K.; Ernzerhof, M. Generalized Gradient Approximation Made Simple. Phys. Rev. Lett. 1996, 77 (18), 3865.

5. Tang, W.; Sanville, E.; Henkelman, G. A Grid-Based Bader Analysis Algorithm without Lattice Bias. J. Phys.: Condens. Matter. 2009, 21 (8), 084204.

6. Schutt, K.; Nayak, P. K.; Ramadan, A. J.; Wenger, B.; Lin, Y. H.; Snaith, H. J. Overcoming Zinc Oxide Interface Instability with a Methylammonium-Free Perovskite for High-Performance Solar Cells. Adv. Funct. Mater. 2019, 29 (47), 1900466.

7. Park, Y. H.; Jeong, I.; Bae, S.; Son, H. J.; Lee, P.; Lee, J.; Lee, C.-H.; Ko, M. J. Inorganic Rubidium Cation as an Enhancer for Photovoltaic Performance and Moisture Stability of $\mathrm{HC}\left(\mathrm{NH}_{2}\right)_{2} \mathrm{PbI}_{3}$ Perovskite Solar Cells. Adv. Funct. Mater. 2017, 27 (16), 1605988.

8. Prochowicz, D.; Runjhun, R.; Tavakoli, M. M.; Yadav, P.; Saski, M.; Alanazi, A. Q.; Kubicki, D. J.; Kaszkur, Z.; Zakeeruddin, S. M.; Lewiński, J.; et al. Engineering of Perovskite Materials Based on Formamidinium and Cesium Hybridization for High-Efficiency Solar Cells. Chem. Mater. 2019, 31 (5), $1620-1627$.

9. Wang, Z.; Lin, Q.; Chmiel, F. P.; Sakai, N.; Herz, L. M.; Snaith, H. J. Efficient Ambient-Air-Stable Solar Cells with 2D-3D Heterostructured Butylammonium-Caesium-Formamidinium Lead Halide Perovskites. Nat. Energy 2017, 2 (9), 17135.

10. Gao, X. X.; Luo, W.; Zhang, Y.; Hu, R.; Zhang, B.; Zuttel, A.; Feng, Y.; Nazeeruddin, M. K. Stable and High-Efficiency Methylammonium-Free Perovskite Solar Cells. Adv. Mater. 2020, 32 (9), 1905502.

11. Turren-Cruz, S. H.; Hagfeldt, A.; Saliba, M. Methylammonium-Free, High-Performance, and Stable Perovskite Solar Cells on a Planar Architecture. Science 2018, 362 (6413), 449-453.

12. Chen, Y.; Yang, J.; Wang, S.; Wu, Y.; Yuan, N.; Zhang, W. H. Interfacial Contact Passivation for Efficient and Stable Cesium-Formamidinium Double-Cation Lead Halide Perovskite Solar Cells. iScience 2020, 23 (1), 100762.

13. Xie, L.; Lin, K.; Lu, J.; Feng, W.; Song, P.; Yan, C.; Liu, K.; Shen, L.; Tian, C.; Wei, Z. Efficient and Stable Low-Bandgap Perovskite Solar Cells Enabled by a $\mathrm{CsPbBr}_{3}$-Cluster Assisted Bottom-up Crystallization Approach. J. Am. Chem. Soc. 2019, 141 (51), 20537-20546. 
14. Min, H.; Kim, M.; Lee, S.-U.; Kim, H.; Kim, G.; Choi, K.; Lee, J. H.; Seok, S. I. Efficient, Stable Solar Cells by Using Inherent Bandgap of $\alpha$-Phase Formamidinium Lead Iodide. Science 2019, 366 (6466), 749-753.

15. Stolterfoht, M.; Wolff, C. M.; Márquez, J. A.; Zhang, S.; Hages, C. J.; Rothhardt, D.; Albrecht, S.; Burn, P. L.; Meredith, P.; Unold, T.; et al. Visualization and Suppression of Interfacial Recombination for High-Efficiency Large-Area pin perovskite solar cells. Nat. Energy 2018, 3 (10), 847-854.

16. Chen, Y.; Yang, Z.; Jia, X.; Wu, Y.; Yuan, N.; Ding, J.; Zhang, W.-H.; Liu, S. Thermally Stable Methylammonium-Free Inverted Perovskite Solar Cells with $\mathrm{Zn}^{2+}$ Doped $\mathrm{CuGaO}_{2}$ as Efficient Mesoporous Hole-Transporting Layer. Nano Energy 2019, 61, 148-157.

17. Zhang, M.; Chen, Q.; Xue, R.; Zhan, Y.; Wang, C.; Lai, J.; Yang, J.; Lin, H.; Yao, J.; Li, Y.; et al. Reconfiguration of Interfacial Energy Band Structure for High-Performance Inverted Structure Perovskite Solar Cells. Nat. Commun. 2019, 10 (1), 4593. 